\title{
LIDERAZGOS FEMENINOS EN LA GESTIÓN POLÍTICA LOCAL DE LA CIUDAD DE TAPACHUla, CHIAPAS: DISCURSOS Y PRÁCTICAS DE PODER
}

\author{
Local Political Advocacy of Women Leaders in Tapachula, Chiapas: Discourses and Practices of Power
}

Aki Kuromiya

Resumen: En el presente artículo se analizan las principales prácticas de mujeres que fungen como lideresas locales en una colonia de la ciudad de Tapachula, Chiapas, orientadas a conseguir apoyos gubernamentales. Mediante casos etnográficos, se evidencia cómo estas lideresas enarbolan en sus discursos algunas cualidades idealizadas de la mujer para legitimar su poder de liderazgo, y a la vez cómo recurren a mecanismos tradicionales de "intermediación" ya pautados, que responden a reglas no escritas de gestión local. En particular, las estrategias asumidas por estas lideresas y sus seguidores son examinadas como herramientas políticas dirigidas a la solución de sus problemas cotidianos.

Palabras clave: gestión política, política local, liderazgo femenino, rol de género, participación ciudadana, intermediación.

Abstract: The purpose of this paper is to analyze the main practices of women from a neighborhood of the city of Tapachula, Chiapas, who take on local leadership roles to obtain governmental support. Through ethnographic case studies, we examine how women leaders' discourses adopt some idealized qualities of women to legitimize their power as leaders. Furthermore, we discuss how they resort to traditional mechanisms of "intermediation" that respond to unwritten local management rules. In particular, we analyze what strategies these leaders and their followers use as politic tools in order to solve their everyday problems.

Keywords: political management, local politics, women's leadership, gender roles, citizen participation, intermediation.

Aki Kuromiya. Doctora en Antropología Social por la Universidad Iberoamericana, A.C. Ciudad de México, México. Docente de asignatura en la Licenciatura en Antropología Social de la Universidad Autónoma de Chiapas, México. Temas de especialización: antropología del desarrollo, urbanización y vivienda, políticas de vivienda. Correo electrónico: akikuromiya@hotmail.com.
Enviado a dictamen: 9 de noviembre de 2017

Aprobación: 8 de mayo de 2018

Revisiones: 2 


\section{Introducción}

E n México y otros países de América Latina existen programas de desarrollo social a cargo de los gobiernos nacionales clasificados como "asistencialistas". Mediante estos programas se otorgan una serie de apoyos, principalmente económicos, a las familias de bajos ingresos, así como otro tipo de recursos destinados a mejorar las condiciones materiales de sus espacios vecinales. Al respecto, un ejemplo en México es el programa Oportunidades — actualmente llamado Prospera-, el cual ha sido estudiado desde perspectivas variadas (Molyneux, 2006; González de la Rocha, 2006; Agudo, 2009; Hevia, 2010, entre otros). Una de las características de este programa es que las mujeres no sólo son vistas como destinatarias del beneficio, sino que también son consideradas como las principales promotoras del desarrollo social. Así, el gobierno -basándose en el criterio de que mejorar la calidad de vida no es una responsabilidad exclusiva del Estado, sino que también le corresponde a la población impulsar cambios en su ambiente cotidiano y familiar - aspira a propiciar en las mujeres el papel de constructoras de su propio destino y del porvenir de sus familias.

Sin embargo, esta mirada política acerca de la "corresponsabilidad" ha sido cuestionada (Molyneux, 2006; González de la Rocha, 2006; Cornwall, 2003; Agudo, 2009), pues mediante ella se refuerza el papel tradicional de las mujeres, ratificando de ese modo aquellas visiones que les reservan el rol de "cuidado" en una forma "natural" a su familia e incluso a su localidad; se asume así, de una manera explícita, que es propio de ellas, como mujeres, una actitud "altruista". Desde este enfoque, se produce una naturalización del rol femenino, a través de la cual se espera que las mujeres cumplan su papel cabalmente, asuman su responsabilidad y no sólo exijan al gobierno. En este sentido, la política pública en la materia y, en particular, los programas de desarrollo social destinados a estos sectores, según Agudo (2009: 64-65), refiriéndose a la "gubernamentalidad" de Foucault, contienen una "tecnología política" por medio de la cual se ejerce la "conducción de las conductas".
No obstante, el mismo autor apunta que existe "el peligro de enfatizar excesivamente el poder de la 'industria' del desarrollo social para controlar a las poblaciones representadas", y advierte por lo tanto sobre la importancia de también prestar atención a las realidades locales de las políticas sociales (Agudo, 2009: 65). Partiendo de este planteamiento antropológico, en el presente artículo analizo los apoyos gubernamentales en tareas de desarrollo social dirigidos a mujeres que figuran como líderes locales en la gestión política de una colonia popular en la ciudad de Tapachula (Chiapas, México). Mediante el análisis de las acciones y los discursos en los que ellas se apoyan para organizar a los habitantes y solicitar los apoyos gubernamentales, el objetivo es evidenciar cómo las mujeres expresan discursivamente su rol de lideresas locales y cómo lo practican en situaciones particulares, así como de qué forma el imaginario de las cualidades femeninas que poseen permea en sus discursos y prácticas políticas. Cabe aclarar, no obstante, que los apoyos a los que me refiero aquí no derivan del programa de Prospera, sino que se trata de otro tipo de apoyos públicos que las lideresas solicitaron directamente al gobierno municipal, estatal o federal, algunos de los cuales son: Programa Piso Firme para la Vivienda, Cruzada Nacional contra el Hambre o Programa Pensión para Adultos Mayores.

A partir de la descripción etnográfica, se notará cómo la "tecnología política" antes referida, que busca otorgar a las mujeres un papel central en el desarrollo social, influye en forma directa e indirecta en sus discursos y prácticas. Es decir, la corresponsabilidad, que el Estado espera de las mujeres, es entendida por ellas como una oportunidad para el logro de la equidad de género en el campo de la política local: de esa manera, bajo esta modalidad de entendimiento, las mujeres creen que adquieren el poder para tomar unas decisiones a favor de ellas, sus familias e incluso su colonia. En la práctica, he observado cómo participaban activamente para solicitar y repartir los recursos, y al hacerlo tenían una expectativa clara de mejorar su calidad de vida.

Pese a ello, no considero que éste sea un caso exitoso de las tecnologías del Estado, las cuales ven a 
las mujeres como depositarias pasivas y naturalizadas a partir del rol tradicional asignado. Si bien ellas enarbolan discursos fundamentados en un imaginario de las cualidades femeninas y relacionan ello con los valores democráticos, tales como la equidad de género, la participación ciudadana o el empoderamiento de las mujeres, entre otros (Massolo, 2003; Nussbaum, 2002), al observar de cerca sus prácticas, el mecanismo político que utilizan ellas como lideresas locales demuestra el predominio de una estructura vertical que puede considerarse como "tradicional" en México (Tapia, 1992; Lomnitz, 2001: Hevia, 2010). Me refiero al mecanismo de "intermediación", según el cual los líderes comunitarios fungen como nudos para la canalización de los recursos y "ponen en contacto a grupos sociales con [la] agencia del Estado" (Tapia, 1992: 443). Los intermediarios reciben, como recompensa por atender a ambas partes, recursos o satisfacción a sus demandas en forma preferencial. Ésta constituye la misma figura del líder que se ha reportado ya en varios estudios en México, incluyendo lo relacionado con el programa Oportunidades (Hevia, 2010: González de la Rocha, 2006; Agudo, 2009). En otros países latinoamericanos, el interés por este asunto también es una tradición de larga data (Lomnitz, 2001; Auyero, 2002; Arriagada, 2013).

Por una parte, las mujeres que conocí como lideresas locales en la colonia Villa Morada asumen su rol tradicional en la gestión política haciendo hincapié en que sus formas de hacer política son más novedosas y democráticas que las de antes - cuando los hombres desempeñaban el papel de líderes-, precisamente porque ellas identifican algunas cualidades idealizadas en las mujeres: "altruistas", "equitativas" y "sensibles". Dotadas de esa valoración, expresaban que podían lograr unas políticas más democráticas y más equitativas porque “así somos las mujeres". Por otra parte, observé que ellas se desenvolvían en escenarios donde la relación vertical por la canalización de recursos seguía vigente: se trata de los actos de corrupción que las mismas lideresas criticaban. Estamos así ante dos aspectos del ejercicio de la gestión política local que resultan contradictorios pero que, en la práctica, conviven. Ambos configuran distintas formas de ejercicio de los poderes, encontradas al buscar soluciones a problemas cotidianos, con base en los conocimientos prácticos localizados.

Inicio haciendo una revisión de los estudios sobre el papel de las mujeres en los programas gubernamentales de apoyo, complementándolos con sus críticas y sus aportes de transformación. Posteriormente ofrezco datos generales sobre el lugar donde realicé mi investigación, para luego detallar la metodología que utilicé. En otro apartado presento las gestiones llevadas a cabo por las mujeres que residen ahí y el proceso que siguen, así como identifico quiénes son las mujeres que fungen como líderes locales y cuáles son sus discursos sobre el papel que asumen. A partir de estos datos, analizo cómo ellas autorrepresentan su condición de género femenino dentro de las prácticas políticas. Finalmente ilustro la relación vertical a la que me refiero apoyándome, como ejemplo, en algunas prácticas locales concretas. En la conclusión, resumo los distintos significados del poder que han asumido las lideresas y sus usos concretos en la práctica política.

\section{El rol femenino en los programas gubernamentales de apoyos}

Massolo $(1999,2003)$ y otros autores (por ejemplo, Ajamil, 1994) señalan como tendencia generalizada en los países latinoamericanos, desde hace unos treinta años, la valoración de las mujeres en el ámbito de los programas de desarrollo social o antipobreza, donde ellas son consideradas, más que en la condición de objetos de apoyo, como agentes de cambio social y protagonistas del mismo desarrollo. Lo que se buscaría así es la adquisición y fortalecimiento del poder, refiriéndose con este último concepto no a la dominación del otro género, sino a la capacidad de las mujeres para: a) incrementar su propia autoconfianza en la vida e influir en la dirección del cambio, y b) ejercer su liderazgo mediante las habilidades para conseguir y tener control sobre ciertos recursos materiales y no materiales (Ajamil, 1994).

Este enfoque de las mujeres como el principal actor de desarrollo social ha sido adoptado y aplicado 
por algunos programas gubernamentales de México. Me refiero, por ejemplo, al programa Oportunidades, cuyo objetivo es contribuir al desarrollo humano de la población en condiciones de pobreza extrema. En este programa, las madres de familia son quienes reciben los apoyos - transferencias de efectivo, becas de educación básica para sus hijos y servicios de salud — directamente gestionados por las instancias gubernamentales para que, a su vez, ellas se encarguen de contribuir al desarrollo humano de los miembros de su familia (Agudo, 2009; González de la Rocha, 2006). Según el estudio de Molyneux (2006), en el trasfondo de este tipo de programas están los conceptos nuevos propuestos por las agendas internacionales del desarrollo, como los Objetivos de Desarrollo del Milenio (ODM), a través de los cuales se enfatiza la promoción de la capacidad de las mujeres para formular y tomar decisiones sobre sus propias necesidades, a través de lo cual ellas dejarían de ser meras "beneficiadas" o "clientes del estado" (Molyneux, 2006: 429).

Es decir, el liderazgo femenino en la participación de los programas gubernamentales de apoyos, junto con la introducción, a partir de las décadas de 1980 y 1990, de la política de descentralización y de la participación ciudadana, representan nuevos paradigmas de la relación entre el Estado y la sociedad civil (Holston, 2008; Hataya, 2009; Sáenz, 2010). Mediante estos programas de "corresponsabilidad", el Estado busca compartir el "riesgo" con la sociedad civil liberándose de su papel paternalista. Algunos estudios explican este giro como un avance político, ya que promueve la equidad de género y el empoderamiento de las mujeres, así como el "capital humano" de quienes ocuparon tradicionalmente un lugar secundario en los programas de desarrollo social. Incluso este giro es considerado como una nueva posibilidad política para practicar una democracia participativa (Nussbaum, 2002; Massolo, 2003).

Sin embargo, este planteamiento ha sido cuestionado desde su raíz conceptual, pues ya desde su fundamento se postula una conducción de los roles femeninos, de modo que, con ello, se contribuye a reforzar el papel tradicional de las madres como únicas encargadas del cuidado de la familia (Molyneux, 2006: 436). De una manera implícita, el programa espera o, más bien, obliga a que las madres sean "buenas" en un sentido universal; es decir, que se comporten como una figura altruista y de autosatisfacción dedicada al cuidado de los otros miembros de la familia. En este sentido, las políticas sociales como Oportunidades están diseñadas para que "los gobernados se constituyan a sí mismos en gobernables" (Agudo, 2009: 65). En general, lo que ello muestra es cómo el Estado ejerce su poder de gobernanza sobre la sociedad.

Si bien esta crítica a la noción de género que asume un programa de apoyo es acertada, lo que observé directamente en el trabajo de campo sobre la gestión local de estos programas gubernamentales fue un entorno en el que participaban las mujeres de un modo activo: ellas estaban muy entusiasmadas por ser agentes en la toma de decisiones que impactaban no sólo sobre ellas mismas o sus familias, sino también a su espacio habitacional, de manera que, bajo esta figura de "mujeres", se encarnaría la visión que busca la agenda internacional del desarrollo. En este sentido, pareciera que la tecnología política tuvo un éxito, pues se naturalizó el liderazgo femenino en la vida cotidiana de las mujeres, haciéndoles creer mediante ese mecanismo que su cualidad "natural" puede aportar a la política local. Efectivamente, ellas no viven de manera contradictoria la superposición de los roles que adoptan como cuidadoras de la familia y como "agentes del desarrollo". Por el contrario, los datos etnográficos que obtuve evidencian una relación estrecha entre su autorrepresentación, a partir de unas cualidades femeninas idealizadas, y la legitimidad que poseen como lideresas locales.

\section{Colonia Villa Morada: primer acercamiento y metodología de investigación}

El municipio de Tapachula se encuentra ubicado en el extremo sur del estado de Chiapas, a cuarenta kilómetros de la frontera con Guatemala. Según los datos del Consejo Nacional de Evaluación de la Política de Desarrollo Social (CONEVAL), en 2015 más de la 
mitad (54.4\%) de los 350000 habitantes del municipio se encontraba en situación de pobreza; de los cuales un $12 \%$ vivía en condiciones de pobreza extrema. ${ }^{1}$

En la ciudad de Tapachula predomina un clima cálido subhúmedo a lo largo del año. Esta condición supone un tipo específico de urbanización y vivienda, lo cual dificulta más la gestión política municipal y su economía. En realidad, durante mi trabajo de campo en esta ciudad noté grandes carencias en cuanto a servicios públicos y una atención insuficiente en materia de condiciones ambientales urbanas; por ejemplo, había una falta de alumbrado público, un sinnúmero de baches en las calles y sólo existían cuatro camiones para el servicio de recolección de basura, ${ }^{2}$ entre otros aspectos. La estadística previa del CONEVAL reporta que un $33.3 \%$ de la población de este lugar sufre de una falta de acceso a servicios básicos en cuanto a vivienda.

Esta situación se agudiza aún más en la colonia Villa Morada. ${ }^{3}$ Ésta carece de alumbrado público, de avenidas para los autos y de agua potable, $\mathrm{y}$, además, hay pocos servicios de transporte público y fallas constantes en el suministro de electricidad. Dicha colonia se encuentra en el extremo sur de la zona urbana, aproximadamente a siete kilómetros de distancia en línea recta del centro de la ciudad. De acuerdo con los datos del Consejo Nacional de Población (CONAPO) de 2010, las estadísticas por Áreas Geográficas Básicas (AGEB) muestran que la población de Villa Morada posee un grado alto de marginación. ${ }^{4}$ Esta colonia se creó como resultado de una política de reubicación de los damnificados de un huracán ocurrido en 2005, y debido a ello las casas fueron otorgadas en forma gratuita por el gobierno federal. Me llamó la atención cómo la gente logró adaptarse a la vivienda construida por un tercero, cuyo diseño es visto por sus propios moradores como un producto muy mal hecho y no apto para el clima tropical de esta ciudad. ${ }^{5}$ En 2017 es uno de los asentamientos más grandes de Tapachula, con una población total de 6460 habitantes y más de dos mil viviendas edificadas. Del total de estas viviendas, cerca de trescientas fueron desocupadas (INEGI,
2010), ya que a muchos beneficiarios del programa de reubicación no les gustó la zona o las viviendas otorgadas, por lo que decidieron vivir en otras zonas de la ciudad o migrar a otras ciudades. Los datos anteriores explican la condición de precariedad generalizada que prevalece en la colonia y, a la vez, que no ha habido muchos apoyos para su mejoramiento; asimismo, evidencian la inconformidad de parte de los residentes respecto a la política de reubicación promovida por el gobierno federal durante 2005 y 2006.

En esta colonia apliqué en total veintiséis encuestas, ${ }^{6}$ principalmente a las mujeres, no porque así lo hubiera planeado, sino por el horario en que llevé a cabo las encuestas - por las mañanas, cuando sólo encontré presentes a las amas de casa, realizando sus labores domésticas o bien atendiendo algún negocio familiar dentro de su casa, comola venta de ropa usada, de comida o de abarrotes-. Durante la aplicación de la encuesta pregunté sobre las condiciones socioeconómicas de la familia y el proceso de otorgamiento de la casa; asimismo, consideré una parte en la que me narraran sus historias de vida después de la reubicación. En el desarrollo de las entrevistas, solían salir a flote las preocupaciones de las personas entrevistadas sobre la precariedad de las condiciones generales de su colonia y sobre cómo su situación económica familiar, muy deteriorada, les impedía invertir en la mejora de la vivienda.

Durante mi trabajo de campo en 2014 visité constantemente a todas las mujeres a las que apliqué las encuestas, para saludarlas y charlar en forma abierta con ellas con el objetivo de ahondar en algunas informaciones. En esas conversaciones, me enteré de la presencia de unas mujeres que fungían como líderes locales. Algunas interlocutoras utilizaban la palabra "representante" y otras la de "presidenta" o "líder". La colonia se compone de tres polígonos y encontré que en cada uno de ellos había una o más personas que se definía como su líder. Parecía que no había una denominación precisa de esta figura; sin embargo, cualquier persona a la que preguntaba por el "líder" o "presidenta" de la zona, me daba los nombres de las mismas personas. En este trabajo uso los términos "líder local" o "lideresa local" como nombres genéricos, 
pero también lo hago en referencia, en parte, a la figura del "líder comunitario" (Lomnitz, 2001; Tapia, 1992), los cuales operan como intermediarios políticos y, como menciono más adelante, finalmente ellas mismas compartían la reproducción de esa figura.

Para acercarme a ellas, en términos de esta investigación, preparé una guía de entrevista para concentrarme en las discusiones principales, pero la mayoría del tiempo la pasé estableciendo entrevistas informales con ellas - en el sentido de que, aunque no estructuré explícitamente las preguntas, dentro de las conversaciones traté de encaminar el tema hacia lo que quería profundizar-. También realicé un ejercicio de observación participante: así, me hacía acompañar por ellas en sus reuniones vecinales, en las reuniones con los funcionarios municipales, o en la resolución de algunas cuestiones vecinales, entre otras actividades.

\section{El liderazgo femenino en Villa Morada: sus prácticas y discursos}

Cada una de las lideresas locales de los tres polígonos tenía una versión diferente sobre cómo llegó a ser líder y sobre el sustento legal o extralegal en el que se apoyaba el acto de desempeñar ese papel. Tampoco había una relación de cooperación entre ellas al respecto; cada una usaba sus propias estrategias y canales personales para realizar la gestión que ello implicaba. Una característica compartida por ellas es que ya habían tenido vínculos con los funcionarios municipales y, además, realizaban algunas gestiones políticas en forma personal por medio de trámites para solicitar recursos para el mejoramiento del espacio público o las viviendas, o apoyos para madres solteras o personas de la tercera edad. También, cuando ocurrían fallas en el servicio público como en el suministro del agua, ellas reportaban y levantaban las quejas ante el gobierno municipal para que se aplicaran las medidas correspondientes. Por ejemplo, como parte de su experiencia ya habían gestionado, en forma separada, la revisión de los tubos de agua rotos, el cambio del drenaje, la instalación de equipos deportivos en el parque público, la restauración del kiosco y la remodelación de las escuelas de la colonia, entre otros asuntos. Es decir, ellas desempeñan el papel de gestoras locales ante los programas de desarrollo social y de repartición de recursos, así como en materia de planeación urbana de su entorno. Por ello, los habitantes a los que apliqué las encuestas coinciden en que la existencia de esta figura es de suma importancia para la vida comunitaria, pues debido a las condiciones socioeconómicas que tienen son necesarios los apoyos gubernamentales para mejorar su calidad de vida.

La forma en la que operan las lideresas es la siguiente: cuando el gobierno municipal, estatal o federal abre algún programa de apoyo - por ejemplo, el financiamiento para colocar cemento en el piso de tierra de las viviendas (programa Piso Firme) - , se avisa al público en general a través de los medios locales y la prensa oficial, y también de forma personal a los líderes locales. A su vez, ellas se encargan de difundir la información mediante perifoneo, convocando a reunión a los interesados para abordar el asunto en cuestión. Los que quieren solicitar los apoyos preparan sus documentos y los entregan a la lideresa del polígono correspondiente, para que ella los entregue a la persona encargada del programa del gobierno municipal o estatal. Muchos habitantes no tienen el conocimiento suficiente sobre qué documentos tienen que presentar y cómo tramitarlos, ya que algunos son analfabetos; ante ello, las lideresas ofrecen su ayuda y orientación. Los recursos otorgados por el gobierno llegan a través de ellas, de modo que se les considera las principales agentes, con responsabilidades y reconocimiento ante los diferentes niveles de gobierno, encargadas de gestionar los apoyos y de distribuirlos entre los habitantes.

A continuación presento a cada una de las lideresas locales, centrándome en el proceso que siguieron para llegar a ocupar la posición de líder, la función que piensan que están fungiendo, así como los discursos que expresan para explicar su rol dentro de la colonia. Mediante ello, retrato cómo ellas viven su rol femenino en la gestión política, y cómo la participación femenina en materia de política social es considerada como algo positivo por ellas mismas. 


\section{Lideresas en el polígono I: Rocío y Juana}

Rocío nació en 1969, tiene dos hijos mayores de edad que viven en otras ciudades de Chiapas, y ahora vive sólo con su esposo. Es maestra de cocina y de corte y confección en los talleres que se imparten en el gobierno municipal. Debido a esta relación tejida con el personal del gobierno municipal, logró realizar varias gestiones a favor del polígono del que forma parte.

Además, ella promovió la instalación de equipos deportivos y la reparación de algunos desperfectos en las instalaciones eléctricas para las viviendas y en las tapas de drenaje, entre otras demandas. Incluso solicitó que se realizara una campaña para la expedición extemporánea de actas de nacimiento ${ }^{7}$ a favor de los vecinos de su colonia. Cuando realicé mi trabajo de campo, también se encontraba demandando recursos al gobierno municipal para iniciar un taller de elaboración de compostas dentro de las viviendas, a fin de que los vecinos del lugar iniciaran el cultivo de pequeños huertos orgánicos. Su objetivo era organizar un tianguis con los productos cultivados y así poder mejorar las condiciones económicas de los residentes. Su principal interlocutor era el gobierno municipal, aunque, a fines de 2014, estaba gestionando paralelamente un programa de apoyo para las madres solteras que ofrecía el gobierno estatal.

Rocío decidió mudarse a esta colonia, dejando su otra casa ubicada en el centro de la ciudad para, por un lado, proteger su patrimonio, y, por el otro, "para atender a la gente necesitada de esta colonia". Ella narró de la siguiente manera por qué decidió vivir en esta colonia:

Yo vine a vivir aquí porque no podía dejar esta colonia como estaba. No es posible que viva la gente en una condición tan miserable. Es una tristeza. La otra que está trabajando desde hace muchos años [se refiere a la líder Juana] comete muchas transas [actos indebidos]. No atiende en forma correcta a las personas. Sólo a su grupo, y los que no están en su grupo, no pueden obtener la ayuda. No debe ser así... ¿Verdad? Tiene que atender a todos Yo sí atiendo a todos. Empecé a meterme para acá, a atender otras personas, jalar el apoyo para acá. Al principio, la gente no me tenía la confianza, pero tengo dos años que trabajo aquí y hay más gente conmigo. ${ }^{8}$

Como lo expresa en su comentario, Rocío disputa la legitimidad de ser líder con Juana —otra residente que funge como lideresa en esta zona-, lanzando críticas a su práctica, la que califica de ejercicio indebido. Rocío quería mostrar quién era más "justa" en cuanto al manejo de recursos y al trato con los vecinos. Así, argumentaba lo que sigue:

Yo no cobro nada a mis vecinos por mis servicios. Cuando quieren darme algo, lo acepto, pero sólo con la voluntad de ellos. A veces tengo que ir hasta Tuxtla Gutiérrez [capital del estado] para entregar un papel al gobernador, ahí los vecinos me ayudan. Pero jamás yo les digo que esto cuesta. ${ }^{9}$

Mencionó que Juana cobraba cincuenta pesos a los vecinos por emitir una carta de comprobante de domicilio como "presidenta de la colonia", y explicó con mucha energía que nadie fuera de la instancia correspondiente podría hacer tal trámite, y mucho menos cobrar por ello. ${ }^{10}$ También criticó claramente la práctica de "hacer favores personales" y sacar provecho de ello.

Es interesante anotar que, para insistir en la legitimidad de su liderazgo, Rocío enfatizaba el valor de la equidad, en contra del favoritismo; es decir, que no se trataba sólo de repartir recursos a los conocidos, sino a los que "realmente lo necesitan", además de no esperar recompensa por ello. Ésta es una expresión que respalda la importancia de ser una "cuidadora" de excelencia y una persona "altruista" que trabaja por los demás sin esperar algún premio.

Juana, la otra lideresa, tenía 42 años en 2014, era ama de casa y dueña de una tienda de abarrotes con concesión de LICONSA, un cierto tipo de prebenda otorgada por el gobierno federal. ${ }^{11}$ Vivía con su esposo y tres hijos varones, todos en edad escolar. Ella señaló que su cargo ya no era de facto como el de Rocío, sino 
que fue asignado por el gobierno federal, ya que era la presidenta local del programa Cruzada Nacional contra el Hambre. ${ }^{12}$ Aseguró, por lo tanto, que nadie podía cuestionar su legitimidad debido a que se le asignó ese cargo mediante una adjudicación oficial de parte de la Secretaría de Desarrollo Social (SEDESOL). Juana mencionó durante la entrevista que en ese momento su interlocutor era el gobierno federal, que contaba con más recursos y programas, en contraste con lo que podía esperarse del gobierno municipal. Mediante este programa, ella esperaba instalar el alumbrado público, ampliar la red de drenaje fluvial y tapar los canales, además de rehabilitar las calles, entre otros asuntos. En 2014 estaba recabando las firmas para solicitar los presupuestos respectivos.

En el caso de Juana, ella venía asumiendo el papel de lideresa local desde antes del desastre natural y jugó un rol decisivo durante el proceso de la asignación y entrega de viviendas gratuitas. Un funcionario público del municipio me explicó que algunos habitantes de esta zona ayudaron a agilizar los trámites para el otorgamiento de las viviendas, canalizando las informaciones con los demás habitantes. Por lo tanto, a estas personas se les otorgó el privilegio de escoger la ubicación de la vivienda en su nueva colonia. ${ }^{13} \mathrm{La}$ vivienda de Juana se encontraba enfrente de la única escuela secundaria de la colonia, sobre la avenida principal, por donde pasaban casi todas las unidades de transporte público. Analizando conjuntamente estos hechos, el poder de Juana como lideresa local no era reciente, sino que se vino consolidando a partir de que ella asumió el rol de "intermediaria" del programa, $y$, debido a que desempeñó dicho papel, el gobierno la recompensó. El hecho de que haya sido escogida como presidenta de la zona para el programa federal también explica su relación con el personal del ayuntamiento.

Pero al principio de la entrevista, cuando le pregunté por qué asumía este papel de liderazgo, antes de presentarse como la presidenta del programa, ella explicó que la gente la elegía y la buscaba para que le apoyara, pues "la gente sabe quién trabaja más duro, [es la] más responsable". ${ }^{14}$ Con el objetivo de responder a las personas que la buscaban y a las necesidades más apremiantes de sus vecinos, ella voluntariamente asumió un papel de liderazgo. Se trataba del mismo discurso defendido por Rocío y otras mujeres, los cuales se abordarán en seguida.

\section{Una lideresa en el polígono 2: miembro afiliado al Partido Revolucionario Institucional}

Perla era la lideresa del polígono 2. Nació en 1973, era madre de tres hijos todavía pequeños y jefa de la familia. Durante la noche se dedicaba a la venta de hot-dogs y tortas en un carrito. Según los datos socioeconómicos que obtuve al aplicar la encuesta, su economía era tan precaria que, sin el apoyo gubernamental actual, sería muy difícil su reproducción diaria.

Perla había promovido en su zona programas gubernamentales como los llamados Piso Firme y Techo Reforzado, ya que, según ella, las viviendas de su área estaban mal construidas desde el principio: había necesidad, por ejemplo, de ampliar el espacio hacia el patio y de cambiar el techo por uno de mejor material. En los primeros años tuvieron problemas con el servicio de agua potable, pues a pesar de que ninguna casa tenía cisterna, sólo una vez a la semana llegaba el agua. Ella se encargó de solicitar y negociar con el gobierno municipal y el comité de agua potable y alcantarillado del municipio de Tapachula el mejoramiento del servicio y así logró el suministro de dos a tres veces a la semana.

En fechas recientes, gracias a su gestión política, el servicio de recolección de basura comenzó a operar en su polígono por lo menos una vez cada quince días. Éste fue un logro que muchos entrevistados destacaron, pues ninguno de los otros polígonos contaba con ese beneficio. Cabe recordar que en 2014 operaban sólo cuatro camiones que se encargaban de la recolección de basura de todo el municipio. Según mis informantes del polígono, Perla pudo realizar esta tarea por estar afiliada al Partido Revolucionario Institucional (PRI), el mismo partido del presidente municipal —coalición del Partido Verde con el PRI-.

Ella se presentó ante mí como "la presidenta de la colonia", esto es, como la encargada - comisionada por parte del gobierno del municipio- de gestionar 
la obra urbana y la planeación de esa colonia, aunque me explicó que su trabajo no se limitaba sólo a planear la obra y presentarla ante el ayuntamiento, sino que también consistía en "ayudar en general a la gente que necesita", pues "mis gentes me tienen confianza y ellos me buscan para que yo les ayude". ${ }^{15}$ Jamás mencionó que su liderazgo dependiera mucho de su condición política; esto es, del hecho de que era miembro afiliado del PRI. Según ella, su confianza se basaba en su incondicional dedicación a atender a sus vecinos, además de lo que ya había logrado en cuanto a mejorar el ambiente de la colonia.

\section{Lideresas en el polígono 3: un comité de mujeres}

En el polígono 3 había un comité de siete mujeres encabezado por una presidenta, Magdalena, tal como ella se presentó conmigo. De acuerdo con lo que ella explicó, un día se realizó una reunión en la que se convocó a los habitantes del polígono para tramitar una obra ante el ayuntamiento en relación con su espacio público y, en esa reunión, decidieron crear un comité que operara como grupo de cooperación, de modo que no destacara sólo una figura que pudiera hacer mal uso de su mandato. Una vez realizada la votación, se eligió a siete mujeres, y luego a ella como presidenta. Las mujeres elegidas aceptaron voluntariamente estos cargos. Me dijo que ella era "la presidenta del comité vecinal”, y explicó que podían haber elegido a hombres, pero se eligieron sólo mujeres. Magdalena visualizó este proceso como muestra de cómo debían realizarse la elección y las gestiones políticas en forma democrática. El mismo comité continuó siendo un cuerpo organizador del polígono después de la primera obra por la cual se estableció.

Magdalena nació en 1969, tenía cinco hijos. En 2014, la hija mayor ya estaba casada y el hijo mayor trabajaba y le ayudaba con sus ingresos a su mamá; los dos hijos siguientes cursaban sus estudios escolares y su último hijo tenía tres años. Su esposo se dedicaba a la venta ambulante de trastes para cocina en comunidades rurales de los alrededores de Tapachula. Me dijo que eran contadas las ocasiones en las que su esposo traía suficiente dinero para que pudieran comer todos hasta quedar satisfechos. A pesar de la condición económica de su familia, me pareció que era una de las más entusiasmadas en practicar su labor de liderazgo, más que las otras residentes que también entrevisté. Me dio esta impresión por la forma de explicarme lo que han logrado al actuar unidas entre mujeres.

Me explicó que todos los asuntos del polígono, frente a los cuales se requería realizar las gestiones políticas para solicitar los apoyos gubernamentales, eran discutidos por los vecinos en una reunión, con el fin de fijar lo que era prioritario y crear un acuerdo amplio entre todos. Esto se hizo, por ejemplo, cuando el comité propuso restaurar el kiosco del centro del polígono. Según la versión de Magdalena, al buscar involucrar a todos se logró tratar los asuntos comunitarios de una forma democrática. Lo explicó de la siguiente manera:

Para que no haya problema, nosotras siempre hacemos
una reunión con los vecinos, para decidir qué hacer
o qué pedir. Unos quieren y otros no; discutimos
y luego votamos. Si la mayoría quiere, entonces lo
hacemos. Aunque uno no quiere, si la mayoría dice
que sí, entonces hay que ceder. Así es la democracia,
iverdad? Todos los asuntos así los decidimos. Por eso,
en este polígono, no hay problemas entre vecinos.

En las conversaciones, reiteraba en varias ocasiones cómo la organización del comité vecinal había logrado crear un consenso entre los habitantes y hacerlo respetar. Su insistencia en la importancia de actuar de forma honesta y "democrática", con buena voluntad, parecía que se vinculaba a su experiencia personal con el anterior líder local de la colonia en donde vivían ella y su familia antes de la reubicación. En el momento de solicitar la vivienda gratuita ante la institución gubernamental encargada, tuvo que pagar 3500 pesos al líder local para que él hiciera y firmara - como un "favor personal" - una carta en la que testificaba que ella era su vecina. Tuvo que hacer eso sobre todo porque los documentos oficiales para demostrar la propiedad legal con que contaba estaban a nombre de su padre, y, como una opción, la institución le pidió esa carta. 
En reiteradas ocasiones ella quería mostrarme que su organización no manejaba las cosas de esa forma. Insistía en que ya no debía existir tal estructura jerárquica, corrupta e incluso vieja, entre el líder local y el político. Ella afirmó: “ahora ya hay buenos políticos que tienen buena voluntad de ayudarnos a mejorar la calidad de vida. Así debe ser, y yo también trabajo así, con dedicación y buena fe". ${ }^{17}$ Nuevamente se observa en estas palabras un discurso que ilustra la concordancia entre la cualidad esperable de ser buen líder y una imagen idealizada de la mujer. La crítica que hacía al líder anterior no sólo reveló una molestia por su práctica indebida, sino también transmitía la percepción de ese rol masculino como una figura autoritaria y paternalista. La figura de mujer en la práctica política, con respecto a su rol tradicional, significaba para ella un cambio que aportaba a todos, porque era así como se realizaba una "democracia de verdad".

\section{Los alcances del liderazgo femenino}

Las mujeres a las que conocí como lideresas locales también desempeñaban el papel de amas de casa en su hogar - en el sentido de que se dedican a atender las necesidades familiares - al mismo tiempo que asumían dicho liderazgo, atendiendo las necesidades de los colonos. Para ellas, las gestiones políticas y las reuniones con los habitantes para informar sobre los apoyos u orientar con respecto a los trámites formaban parte de sus prácticas cotidianas. Es decir, su involucramiento en el trabajo doméstico y, a la vez, en gestiones ante instancias de gobierno, estaba en la misma línea de lo que implicaba "atender las necesidades diarias" (Barrera y Aguirre, 2003: 142; Massolo, 1999). Incluso, ellas buscaban activamente asumirse como agentes del cambio social y proponerse el objetivo de crear un nuevo orden en la vida cotidiana de los polígonos, para con ello elevar la calidad de vida de su entorno. Su papel femenino, de esta forma, no se percibía como algo impuesto y comisionado, sino que se trataba de un ejercicio que se reproducía activamente en el marco de la gestión política: así, la cualidad de ser "altruista" y "cuidadora" se traducía en la "confianza" de sus vecinos, y, por consiguiente, les permitía adquirir un poder importante en su ámbito —en el sentido de ejercer la toma de decisiones a favor de ellas mismas y su localidad-. También surgió en ellas una imagen de mujer muy ligada a los valores democráticos de participación y equidad, ya que sabían que esa era la imagen deseada por el gobierno y que les permitía negociar el acceso a los apoyos.

Si se siguen las críticas de corresponsabilidad dirigidas al programa, como la que plantea Molyneux (2006: 438) ya analizada previamente, la figura de lideresa local de Villa Morada sería un caso exitoso de la aplicación de "tecnología política", pues sería una forma de dominación naturalizada de acuerdo con la cual las mujeres trabajan por los demás, asumen una responsabilidad política en su localidad, e incluso vivencian un sentimiento de satisfacción personal por el hecho de servir a la comunidad. Desde este punto de vista, el Estado se aprovecharía de la necesidad que tienen las mujeres de sentirse reconocidas - por sus pares, familiares y vecinos-, así como del deseo de ejercer el poder a través de la toma de decisiones, y de la aspiración por transformar las condiciones de vida de sus barrios. De ese modo, los programas y las instancias gubernamentales que otorgan los apoyos utilizan las necesidades y deseos de las propias mujeres para luego promover ese tipo de agencia.

A mi juicio, sin embargo, no es adecuado encasillar a las mujeres lideresas referidas sólo como entes pasivos y gobernados naturalmente por una tecnología política. Más bien, considero que ellas también perseguían sus propias expectativas e intereses mediante políticas que las incorporaran como agentes centrales del desarrollo social porque, como ya mencioné al referirme a ese discurso, ellas a lo largo del proceso también conseguían construirse a sí mismas - logrando una mayor confianza, legitimidad y poder - en la búsqueda de soluciones a sus problemas cotidianos y aspirando a elevar la calidad de vida de sus ámbitos.

Alejandra Massolo propone un reconocimiento de los liderazgos femeninos ya que de esta forma "logran visibilidad protagónica, adquieren y ejercen poder en el radio del espacio social y político local" (Massolo, 
1999: 87). Es decir, mediante las prácticas políticas y las gestiones ante los programas gubernamentales, las mujeres crecen como sujetos sociales y ciudadanas, además de que reconocen y reivindican sus derechos como ciudadanas y mujeres (1999: 81). De esta forma, las mujeres logran "empoderarse" al actuar sobre las condiciones que les rodean. Este ejercicio del poder por parte de las mujeres es visto como una práctica no paternalista, es decir, como una acción de poder no controlada por los hombres — quienes se impusieron universalmente como poseedores del poder y administradores de la política local- Bajo esta mirada, las acciones de las mujeres expresarían una serie de cambios positivos, así como una capacidad de autogestión y proactividad, entre unos ciudadanos que asumen valores democráticos de un mayor alcance (Nussbaum, 2002; Massolo, 2003; Barrera y Aguirre, 2003).

Estos discursos sobre la figura femenina dentro de la agenda política respaldan y consolidan los significados de la participación femenina que predominan en el ámbito de la política local (Barrera y Massolo, 2003). La política municipal también está experimentando este giro en la búsqueda de una política más equitativa y democrática. El ayuntamiento de Tapachula, por ejemplo, promueve activamente la participación ciudadana en la toma de decisiones y en sus acciones pondera la figura de las mujeres. ${ }^{18}$

Si bien el hecho de asumir y cumplir con un rol tradicional — como mujeres - es una herramienta que forma parte de la estrategia política de las lideresas, no es un producto de la dominación naturalizada desde el Estado, sino una herramienta discursiva que utilizan ellas mediante la cual obtienen ventajas; esto es, logran consolidar su legitimidad y responder a lo que espera el ayuntamiento, para así facilitarse un acceso a recursos. Es decir, mi análisis es que los discursos que postulan una democracia equitativa basada en la cualidad de las mujeres son una parte de una estrategia útil y, como sostengo en el siguiente apartado, su técnica de gestión local está lejos de encarnar su discurso: me refiero a la práctica de "intermediación". Esta práctica es la otra pieza clave que moldea esa estrategia política local. En tal sentido, observé que al final existe una estructura de canalización de apoyos, de tipo vertical y jerarquizada, que precisamente las lideresas rechazan y critican bajo el discurso de una democracia equitativa; pero advierto que, pese a todo, tales prácticas tradicionales han persistido, pues son funcionales para los fines de los habitantes al permitirles acceder de forma efectiva a recursos importantes.

\section{¿Intermediaria tradicional o nueva agente de cambio social?}

Ellas como lideresas locales no obtenían ninguna remuneración oficial ni de parte de vecinos ni del municipio, aunque los que solicitaban los apoyos sí contribuían con algo - papelería, dinero para el transporte, agua o refresco, crédito para el teléfono móvil, etcétera-. Es interesante mencionar que varios estudios reportan un papel similar de los líderes locales en México, en el ámbito urbano o en las comunidades indígenas (Tapia, 1992; Lomnitz, 2001; Nuijten, 2003; Hevia, 2010). En esta literatura antropológica, los líderes se escenifican como unos intermediarios que carecen de remuneración alguna, pero sí obtienen algunas ventajas, bien sea a partir de las cuotas que aportan las demás personas para los gastos de la logística de gestión, bien por ser los primeros en recibir los beneficios, o bien al momento de repartir los apoyos entre sus amistades y familiares como favores personales.

La relación vertical promueve una intermediación a través de la cual se "canalizan los recursos desde la cúspide hacia la base, mientras la lealtad y el apoyo político irradian desde la base hacia la cúspide" (Lomnitz, 200l: 245). El líder local desempeña el rol de intermediario con otros sectores superiores a los que las poblaciones ordinarias no tienen acceso. Así, los líderes buscan canalizar y regular los recursos respectivos, así como distribuirlos a sus asociados clave, a cambio de lealtad hacia ellos mismos y hacia sus superiores.

Esta descripción explica acertadamente el liderazgo que asumen las mujeres de Villa Morada, aunque ellas también reiteraban que en sus casos no prevalecían relaciones asimétricas ni "favoritismo" alguno como sí 
lo había anteriormente - cuando los hombres eran los líderes-, ni tampoco algún tipo de "compra de votos" de parte del gobierno municipal o estatal. Como se trató en párrafos previos, la legitimidad de las lideresas parecía proceder de la honestidad que mostraban ante las poblaciones de su localidad, y en razón a los actos altruistas que expresaban al ayudar a las distintas personas. Para reforzar lo dicho antes, es preciso recordar tanto a Rocío, que criticaba a Juana, justamente porque sólo repartía entre sus amigos y familiares, como a Magdalena, que estaba en contra del mal uso de los recursos que hizo el líder local anterior.

No obstante, al convivir más tiempo con ellas participando en las reuniones importantes que realizaban y en los momentos en que hacían sus trámites burocráticos, me percaté de que había mecanismos que operaban para poner en práctica las políticas locales que podrían calificar como una estructura "vertical". Dentro de ésta, las mujeres como lideresas locales asumían el papel de "intermediación" con respecto a los apoyos, de manera que constituían una parada obligatoria de las solicitudes y los recursos, en general reconocida tanto por los vecinos, como por el personal de las instancias gubernamentales.

Por ejemplo, un día de finales de agosto de 2014 por la mañana, participé en una reunión que convocó Rocío. El punto de encuentro era el estacionamiento del polígono l. Rocío dialogaba con sus convocados, que eran más de cincuenta personas, entre hombres y mujeres de distintas edades. Dos temas de la agenda eran el trámite de la escritura pública de sus viviendas otorgadas por el gobierno y las indicaciones precisas sobre el proceso que debían seguir en ese asunto. También informó que ella había sido asignada como encargada de un programa estatal de apoyo orientado a las madres solteras, el cual había solicitado directamente en la capital de Chiapas al gobernador. Insistió en que no se confundiera éste con otros programas de apoyo que también beneficiaban a madres solteras, pues el que estaba a su cargo era uno de nueva creación que correspondía al gobierno estatal, de modo que, debido a esto, ella era la "única" representante de la zona para acceder a ese apoyo. Y luego explicó detalladamente qué tipo de documentos oficiales se requerían para ese programa. Pude observar que la gente escuchaba en forma atenta lo que les indicaba.

La reunión duró más de dos horas, tiempo en que las personas asistentes cambiaban de lugar para estar bajo la sombra y, antes de terminar, Rocío constató la lista de asistencia en un cuaderno. En ese momento, una persona preguntó si necesitaba "algo". Rocío se dirigió a todo el público: "a ver, zquién recibió mi mensaje de celular?" La mayoría alzó la mano. Y siguió: "pues, iaunque sea el costo del mensaje!, ¿no?" Así, al firmar la lista de asistencia, casi todos le entregaron de cinco a diez pesos, y hubo algunos que le dejaron hasta cincuenta pesos diciendo: "para su refresco". Observé, además, que algunos vecinos enviaban mensajes a sus familiares o sus conocidos para que llegaran a anotarse, por lo que en la lista de asistencia se registraron más de ochenta personas.

Rocío, a pesar de su crítica, finalmente era una figura de esa intermediación que controlaba un programa político y se constituía en un "nudo" de su canalización, a la vez que sacaba provecho de ello de alguna forma. Magdalena, de igual modo, no se olvidaba de pedir, aunque fueran cinco pesos, a las mujeres que se acercaban para que ella llevara la solicitud de apoyo personalmente. Otras entrevistadas operaban más o menos de la misma manera. Hevia, al analizar el mecanismo de intermediación del programa Oportunidades, explica que este tipo de aportación de los vecinos se entiende como un "apoyo" o "contra entrega" de don (Hevia, 2010: 121), pues la función de los líderes — quienes orientan en el trámite, canalizan las solicitudes y manejan recursos para mejorar los espacios públicos - es concebida por la mayoría de los habitantes como un acto de "don", basado en la buena voluntad personal que brindan a todos. En el caso de Villa Morada, no ahondé en cómo concebían los habitantes sus "pagos", pero lo que sí pude constatar es que la mayoría de los vecinos estaban convencidos de que les daban "algo" para que pudieran seguir trabajando de forma correcta y se atendiera su necesidad. Es decir, para los habitantes también era una forma de batallar con los problemas inmediatos, 
pues asumían que de esa forma la lideresa seguiría trabajando a favor de ellos y de su colonia.

Mi análisis de esta práctica es que el discurso sobre el liderazgo femenino y el mecanismo de intermediación son herramientas utilizadas por ellas y otros habitantes para redireccionar la conducción de una "tecnología política" externa a su favor. Es decir, el discurso y la intermediación se basan en la disposición de los conocimientos prácticos de los mismos participantes -incluyendo a los habitantes de la colonia - para poder solucionar problemas de la vida diaria y así mejorarla, aprovechando intencionalmente la conducción del papel de la mujer, pero utilizando el mecanismo funcional. Esta forma de redirección o manipulación del papel de la mujer se observa de diferentes formas. Un ejemplo es un comentario que hizo Rocío al explicar un apoyo estatal dirigido a madres solteras en la reunión arriba descrita. Ella dijo a todos que iba a avisar cuándo llegaría de la capital el funcionario encargado: "ipara que vayan pensando a ver cómo esconden a su marido! Ese día, los hombres no deben estar por acá". Manipulaciones de este tipo por parte de las mujeres beneficiarias para conseguir apoyos son recurrentes y han sido reportadas por varios estudios (González de la Rocha, 2006: Agudo, 2009). Según Agudo, se trata de crear una imagen de mujeres "solas" o "abandonadas" que buscan el programa, a través de la cual puede observarse que los efectos de la "gubernamentalidad" no son directos, por lo que ésta se encuentra manipulada, traducida y aprovechada (Agudo, 2009: 86).

Lo que prevalece en estas prácticas políticas es una lógica funcional para la solución de los problemas. La manipulación de la imagen de las mujeres - ya sea como una agente nueva, más democrática, o como abandonada-, el discurso que promueve una política más equitativa y el mecanismo de la intermediación, en conjunto, son herramientas que han sido generadas y utilizadas por las lideresas y sus vecinos. Incluso constituyen rasgos dinámicos que están en continuo proceso de modificación, renovación y reproducción, de acuerdo con lo que buscaría la política social y las mismas personas beneficiadas.

\section{Reflexiones finales}

Los datos etnográficos presentados señalan que, cuando las mujeres asumen como suyo el papel "tradicional" de servidoras de la comunidad, con ello expresan una forma de legitimar y consolidar un "poder" que recae en ellas. Desde esta mirada pueden hacerse dos lecturas sobre esta noción de poder: la primera, en el sentido de que se trata de una herramienta que les permite la toma de decisiones políticas - una práctica anteriormente comisionada al hombre-, de tal forma que puedan gestionar directamente lo que realmente ellas quieren y necesitan; y, la segunda, en el sentido de que ése es un poder mediante el cual ellas se ubican en un lugar privilegiado ante los habitantes de la colonia y controlan así los recursos como intermediarias. El primer poder se construye y consolida mediante los discursos acerca de las cualidades de las mujeres y se valora como una base de la participación ciudadana en esta zona urbana. El segundo tipo de poder se reproduce dentro de una estructura localizada en la que el único cambio que sobresale es el nuevo papel asumido por las mujeres.

Las diferentes formas de poder manifiestan las características de la gestión política local realizada por las mujeres: ellas y sus habitantes no tienen ni les interesan reglas establecidas de cómo hacer política. Más bien, ven a los mecanismos de ésta como herramientas que surgen en el curso de la solución de sus problemas cotidianos. En este sentido, los discursos y prácticas de la gestión local hecha por las mujeres, así como sus contradicciones, no deben entenderse como algo ya establecido y permanente, sino más bien como un proceso que revela cómo ellas intentan crear un entorno habitacional más cómodo e idóneo. De igual forma, las figuras de poder van cambiando a lo largo del proceso y de acuerdo con los intereses de los actores locales.

\section{Notas}

${ }^{1}$ Datos de CONEVAL, "Anexo estadístico de pobreza a nivel municipio 2010 y 2015", disponible en: https:// www.coneval.org.mx/Medicion/Paginas/AE_pobreza municipal.aspx (consultado el 12 de marzo de 2018). 
${ }^{2}$ Entrevista al Secretario de Desarrollo Urbano y Ecología, agosto 2014.

${ }^{3}$ El nombre de la colonia y de las personas que se citan en este artículo han sido modificados para proteger su privacidad.

4 Datos del CONAPO, disponibles en: http://www. conapo.gob.mx/work/models/CONAPO/indices margina/marginacion_urbana/AnexoA_2/Mapas/59 Tapachula_de_Cordova_y_Ordonez.pdf (consultado el 12 de marzo de 2018).

${ }^{5}$ Así me lo explicaron con respecto a las viviendas de la colonia no sólo los habitantes de la colonia, sino también los mismos funcionarios públicos del ayuntamiento. También en notas periódicas se reportaban y problematizaban las condiciones de la colonia.

${ }^{6}$ La investigación inicial fue pensada para los fines de mi tesis doctoral. El trabajo de campo se realizó en 2012, 2014, y 2015. En 2014 estuve en esta colonia durante tres meses aplicando cuestionarios y entrevistas.

${ }^{7} \mathrm{El}$ acta de nacimiento se debe tramitar durante los tres meses posteriores al nacimiento. Es uno de los documentos de identificación más importantes para la población mexicana, pero en el municipio de Tapachula, por diversas razones, el 2.3\% de la población total, cerca de 8000 personas, no cuentan con este documento (INEGI, 2015). Para los que se encuentran en esa situación, existe el trámite de la expedición extemporánea del acta. Sin embargo, por el costo que implica y los documentos que pide la instancia correspondiente, no es común que se realice ese trámite. Rocío ayudó durante meses a sus vecinos para que prepararan los documentos necesarios y logró que se colocara una ventanilla temporal en su colonia para atender la expedición de actas extemporáneas. El día que se instaló la ventanilla temporal en la colonia, se observó una fila bastante larga de personas esperando para realizar los trámites.

${ }^{8}$ Entrevista estructurada a la lideresa Rocío, agosto de 2014.

${ }^{9}$ Entrevista estructurada a la lideresa Rocío, agosto de 2014.

${ }^{10}$ Lo expresado por Rocío es correcto: la expedición del comprobante de domicilio no le corresponde a un "líder local"; sin embargo, muchos trámites oficiales o públicos requieren de dicho comprobante, y para quienes no cuentan con el servicio de teléfono ni han contratado legalmente el servicio de electricidad - como suele ser costumbre-, es una práctica recurrente pedirle al líder tal comprobante.

${ }^{11}$ LICONSA es "una empresa de participación estatal mayoritaria, industrializa leche de elevada calidad y la distribuye a precio subsidiado en apoyo a la nutrición de millones de mexicanos, especialmente de niños y niñas de hasta 12 años, de familias en condiciones de pobreza, contribuyendo así a su adecuada incorporación al desarrollo del país". Además, tiene su propio programa de apoyo para canalizar algunos abarrotes básicos a bajo precio (ver: https://www.gob.mx/liconsa/es/accionesy-programas/conoce-liconsa. Última consulta: 3 de marzo de 2018).

${ }^{12}$ Es un programa federal diseñado por el gobierno del presidente Enrique Peña Nieto (2012-2018). En el caso de las áreas urbanas, este programa se enfoca en mejorar las infraestructuras de dichos espacios.

13 Entrevista al Secretario de Desarrollo Urbano y Ecología, agosto de 2014.

${ }^{14}$ Entrevista estructurada a la lideresa Juana, agosto de 2014.

${ }^{15}$ Entrevista estructurada a la lideresa Perla, agosto de 2014.

${ }^{16}$ Entrevista semiestructurada a Magdalena, agosto de 2014.

${ }^{17}$ Entrevista semiestructurada a Magdalena, agosto de 2014.

${ }^{18}$ En la página del gobierno municipal de Tapachula, existen muchas notas que reportan cómo la actual administración pone atención en la equidad de género e incorporación de las mujeres en diversas actividades políticas (ver: http://portal.tapachula.gob.mx/sala-deprensa, consultado el ll de marzo de 2018). También el gobierno estatal de Chiapas creó la Secretaría de Equidad y Empoderamiento de las Mujeres, la cual se encarga de impartir talleres a los funcionarios públicos sobre sensibilización en equidad de género y capacitación a las mujeres sobre prácticas empresariales y políticas. (ver: http://www.sedem.chiapas.gob.mx/ inicio, consultado el 11 de marzo de 2018). 


\section{Referencias}

Agudo Sanchíz, Alejandro (2009). "Conocimiento, lenguaje, poder e intermediación. Perspectivas contemporáneas en la antropología de las políticas públicas". En Estudios Sociológicos, 27(79): 63-110.

Ajamil, Menchu (1994). "Cooperación internacional, género y desarrollo". En Revista Iberoamericana de Educación, 6: 103-119.

Arriagada, Evelyn (2013). "Clientelismo político y participación local: El rol de los dirigentes sociales en la articulación entre autoridades y ciudadanos en Santiago de Chile". En Polis, 36: 2-17.

Auyero, Javier (2002). "Clientelismo político en Argentina: doble vida y negación colectiva". En Perfiles Latinoamericanos, 20: 33-52.

Barrera, Dalia y Alejandra Massolo (comps.) (2003). El municipio: Un reto para la igualdad de oportunidades entre hombres y mujeres. México: Grupo Interdisciplinario sobre Mujer, Trabajo y Pobreza, A.C. e Instituto Nacional de las Mujeres.

Barrera, Dalia e Irma Aguirre (2003). "Liderazgos femeninos y políticas públicas en favor de las mujeres en gobiernos locales en México". En Dalia Barrera y Alejandra Massolo (comps.), El municipio: Un reto para la igualdad de oportunidades entre hombres y mujeres. México: Grupo Interdisciplinario sobre Mujer, Trabajo y Pobreza, A.C. e Instituto Nacional de las Mujeres, pp. 105-17.

Cornwall, A. (2003). "Whose Voices? Whose Choices? Reflections on Gender and Participatory Development". En WorldDevelopment, 31(8):1325-1342.

González de la Rocha, Mercedes (coord.) (2006). Procesos domésticos y vulnerabilidad. Una perspectiva antropológica de los hogares con Oportunidades. México: CIESAS, Publicaciones de la Casa Chata.

Hataya, Noriko (2009). La ilusión de la participación comunitaria: lucha y negociación en los barrios populares de Bogotá, 1992-2003. Bogotá: Universidad Externado de Colombia.

Heviadela Jara, Felipe(2010). “Usopolíticodeprogramas sociales y nuevos intermediarios institucionales: el Programa Progresa/Oportunidades en el sur de Veracruz". En Desacatos, 34: 119-132.

Holston, James (2008). Insurgent Citizenship: Disjunctions of Democracy and Modernity in Brazil. Princeton/Oxford: Princeton University Press.

INEGI (Instituto Nacional de Estadística y Geografía) (2010). Censo de población y vivienda. Principales resultados por localidad. México: INEGI.

INEGI (Instituto Nacional de Estadística y Geografía) (2015). "Panorama sociodemográfico de Chiapas". Disponible en: https://bit.ly/2Fu3yDX (consultado el 12 de marzo de 2017).

Lomnitz, Larissa (2001). Redes sociales, cultura y poder. Ensayo de antropología latinoamericana. México: FLACSO.

Massolo, Alejandra (1999). "Las mujeres y el hábitat popular: icooperación para la sobrevivencia o para el desarrollo?" En Anuario de Hojas de Warmi, 10: 79-89.

Massolo, Alejandra (2003). "Políticas públicas locales de equidad de género: Una innovación de la gestión municipal". En Dalia Barrera y Alejandra Massolo (comps.), El municipio: un reto para la igualdad de oportunidades entre hombres y mujeres. México: Grupo Intedisciplinario sobre Mujer, Trabajo y Pobreza, A.C. e Instituto Nacional de las Mujeres, pp. 11-54.

Molyneux, Maxine (2006). "Mothers at the Service of the New Poverty Agenda: Progresa/Oportunidades, Mexico's Conditional Transfer Programme". En Social Policy \& Administration, 40(4): 425-449.

Nuijten, Monique (2003). Power, Community and the State: The Political Anthropology of Organisation in Mexico. Londres: Pluto Press

Nussbaum, Martha (2002). Las mujeres y el desarrollo humano: el enfoque de las capacidades. Barcelona: Herder. Sáenz Acosta, Hernando (2010). "Reseña del libro La ilusión de la participación comunitaria: lucha y negociación en los barrios populares de Bogotá. 1992-2003". En Territorios, 23: 161-165.

Tapia, Jesús (1992). Intermediación social y procesos políticas en Michoacán. Zamora, México: El Colegio de Michoacán. 